\title{
Profile and Pattern of Suicide Attempts Among Admitted Patients in A Teaching Hospital: A Retrospective Study from Nepal
}

\author{
Bigya Shah ${ }^{1 *}$, Pooja Patnaik Kuppili ${ }^{2}$, Tanay Maiti ${ }^{3}$, and Sundari Joshi ${ }^{4}$ and Shreeja Shah ${ }^{5}$ \\ ${ }^{1}$ Lecturer, Department of Psychiatry, Patan Academy of Health Sciences, School of Medicine, Patan, Nepal \\ ${ }^{2}$ Assistant Professor, Department of Psychiatry, Sri Venkateshwara Medical College Hospital and Research Center, Puducherry, India \\ ${ }^{3}$ Psychiatrist, Department of Psychiatry, All India Institute of Medical Sciences, Bhubaneshwar, India \\ ${ }^{4}$ Nursing Director, Nagarik Community Teaching Hospital Limited, Madhyapur Thimi, Nepal \\ ${ }^{5}$ Medical Officer, Clinical Health Care Centre, Nepal \\ *Corresponding Author: Bigya Shah, Lecturer, Department of Psychiatry, Patan Academy of Health Sciences, School of Medicine, \\ Lagankhel, Patan, Nepal. E-mail: shahbigya@gmail.com
}

Received: November 27, 2019; Published: November 29, 2019

DOI: $10.31080 /$ ASMS.2019.03.0488

\begin{abstract}
Introduction: Suicide is a global health concern and one of the leading cause of death among young population worldwide, including in Nepal. Research addressing geographic and socio-cultural variation and gender differences is few in Nepalese setting. The current study is aimed to explore socio-demographic and clinical characteristics, patterns and gender differences of suicide attempts among patients admitted in a teaching hospital.

Methodology: This was a retrospective study conducted for a year in a teaching hospital in Bhaktapur. It included patients presenting with history of suicidal attempt, seeking in-patient treatment and been evaluated by a psychiatrist.

Results: Twenty-six patients were enrolled. Suicide attempts were common in young females belonging to indigenous community. Attempts were predominantly impulsive in nature triggered by mostly psychosocial stressors, interpersonal conflict being the most common, in subjects with underlying psychiatric comorbidities and easy availability of means of suicide such as poisons and medication overdose. Gender difference was present in methods of suicide attempt and attempts made during alcohol intoxication. Majority of patients were first time attempters.

Discussion: This study imparts need of studies with robust methodologies to study suicide. Prevention strategies should be tailored to address gender differences, different age-groups, socio-cultural-economic background and psychiatric comorbidities of the population and geographic variations of the community.
\end{abstract}

Keywords: Suicide; Nepal; Impulsive; Self- Poisoning; Organophosphorus

\section{Abbreviations}

NSAID: Non-Steroidal Anti-Inflammatory Drug

\section{Introduction}

Suicide is a global public health concern. About 80,000 people die by suicide every year and over 16,000000 people attempt suicide per year worldwide [1]. Infact, suicide was the second most leading cause of death among 15 - 29 yrs old in 2012 and the third leading cause of death in $15-19$ years. It is estimated that by 2020 ,
1.5 million people will die each year by suicide and between 15 - 39 million will make a suicide attempt. Low and middle income countries accounted for $75 \%$ of global suicides [2] and 39\% of global suicides occurred in South- East Asia region alone.

Nepal is not spared from this phenomenon. Political instability, past civil wars and maoist insurgency, recent earthquakes, frequent natural disasters, poverty, unemployment, migration, stigma, 
huge treatment gap, mental health on low priority by government, changing societies, easy availability of insecticide and pesticides make Nepalese susceptible to mental health issues and suicide. There is no national data currently to estimate the suicide prevalence but suicide often makes headlines in newspapers. In 2012 WHO had estimated an age-standardized suicide rate of 24.9 per 1000,000 in Nepal. Thereby, Nepal ranked $7^{\text {th }}$ in the world [1]. Similarly, estimated suicide rate of females in Nepal ranks $3^{\text {rd }}$ highest and male rate ranks $17^{\text {th }}$ highest. The pilot study of National Mental Health Survey, Nepal showed current prevalence of suicidality i.e. for past month was $10.9 \%$ among adults. This was carried out only in 3 districts of Nepal with 1647 participants aged 18 years and more [3]. Therefore this may be a tip of the iceberg phenomenon. Furthermore, data by the police of 1 year period 2015-2016 AD calculated crude suicide rate to be $16.4 / 1,00000$ [4]. Community based studies highlight suicide as leading killer in women of reproductive age group [5]. Hence, suicide is indeed a silent epidemic of Nepal [4].

Most of the suicide research in Nepal have taken place in Kathmandu, the capital city of Nepal. Bhaktapur district, located in the eastern part of Kathmandu, remains unexplored. It is the smallest district of Nepal with population about 3 hundred thousand and with four municipalities [6]. Its district headquarter is Bhaktapur city, a sub metropolitan city, 8 miles from Kathmandu. One study done in 2003 in Bhaktapur district hospital found increasing trend in suicide during 2000 - 2002. Females were the predominant cases and zinc phosphide was found to be the most common cause [7].

General hospital psychiatry units play an important role in management of mental health problems. They make psychiatric services accessible to the patients as patients wouldn't readily come to seek help of a psychiatrist directly due to stigma [8]. Hence it is imperative to explore patterns of suicide of Bhaktapur so that suicide prevention strategies can be devised for the country taking all the socio-cultural and geographical variation.

The objective of the study is to explore socio-demographic and clinical characteristics, patterns and gender differences of suicide attempts among patients admitted in a teaching hospital.

\section{Materials and Methods}

The study was carried out at Nagarik Community Teaching Hospital. It is a 100 bedded hospital located in Madhyapur Thimi municipality of Bhaktapur district. It has emergency, inpatient, outpatient services and also has a college for nurses (PCL, BN, BSc) and health assistants. Psychiatrist consultation is done on on-call basis for the emergency and admitted patients and there is a separate outpatient psychiatry service. As a part of consultation liaison, after receiving consultation, detail work up is done interviewing patient and family members. Diagnosis is done according to ICD -10 and treatment is provided.

This was a retrospective study. Medical records of those subjects who were admitted to Nagarik Community Teaching Hospital between March 2018-February 2019 with history of suicidal or self harm attempt were reviewed.

The inclusion criteria for the study were:

1. Patient of any age group admitted to Nagarik Community Teaching Hospital, Gatthaghar between March 2018-February 2019.

2. Presentation with history of suicidal attempt at emergency or other department outpatient clinic.

3. Complete evaluation done by a psychiatrist.

The exclusion criteria for the study were:

1. Those admitted with accidental poisoning.

\section{Study procedure}

The clinical records of those subjects who were admitted in any department of Nagarik Community Teaching Hospital between March 2018-February 2019 with presentation of suicidal or self harm attempt were screened by authors. The records were obtained from the medical record section of the hospital by the author. For the study, suicidal attempt was defined as self-injurious behaviour with nonfatal outcome accompanied by explicit or implicit evidence that the person intended to die. Poisoning was defined as self- exposure of an individual (by ingestion or inhalation or injection) to an amount of substance with the significant potential to cause harm with the intention to die. Overdose was defined as ingestion or application of a drug or other substance in quantities greater than are prescribed or generally recognized therapeutic dosage with the intention to die. Similarly, impulsivity was defined as absence of proximal planning or preparations. Those patients who fulfilled the criteria, their medical records were chosen. Details of the information regarding socio-demographic profile, suicidal attempt, its means, source of poison/ medication, precipitat- 
ing factor, past and family history of psychiatric illness, history of substance use, mental state examination findings, diagnosis made as per ICD-10, treatment provided, number of follow-ups after first visit were noted. Permission was taken from the hospital medical director.

\section{Statistical analysis}

Data analysis was carried out using SPSS version 21. Sociodemographic and clinical profile data including details of suicidal attempt were analysed using descriptive statistics. Group division was done on the basis of gender and males and females were compared on socio-demographic, clinical variables including profile of suicidal attempt using chi square test or Fisher's test (categorical variables) and independent sample t test (continuous variables).

\section{Results}

Out of 68 patients who were admitted during one year duration, eight patients were either referred or discharged on request or sent on leave against medical advice. Therefore, they were not examined by a psychiatrist and could not be included in the study. Remaining 60 patients were admitted in the hospital. Further, there were 34 records with no evaluation from a psychiatrist and had to be excluded. Only 26 patients were examined by psychiatrist and hence included in the study. All the consultations were from medicine department.

\section{Sociodemographic characteristics}

The sociodemographic data (Table 1) shows that the mean age of the patients was 26 (7.9) years. About two-thirds of the patients were young adults (20-35 years) followed by adolescent age group (26.9\%). The youngest patient was 15 years and the most senior was 50 yrs. Females (57.7\%) were more than males $(42.3 \%)$. Predominantly the patients were Janajati (indigenous) (65.4\%) followed by Brahmins (15.4\%) and chhetri (11.5\%). About twothirds of the patients were educated below class 10 , out of which two were illiterate. Most of the patients were married (57.7\%). Majority were Hindu (84.6\%) followed by Buddhist (15.4\%). The patients were predominantly from Bhaktapur district itself (73.1\%). 26.9\% of the patients were from neighbouring districts such as Kavre followed by, Ramechhap, Sindhupalchowk and Lalitpur. Nearly half of the sample was employed, and students and housewives were one-fourth each. Only two were involved in commercial farming.

\begin{tabular}{|c|c|}
\hline Variables & Frequency(\%)/ Mean(S.D.) \\
\hline \multicolumn{2}{|l|}{ Age group category } \\
\hline $14-19 y r s$ & $7(26.9)$ \\
\hline $20-35 y r s$ & $17(65.4)$ \\
\hline $36-59 y r s$ & $2(7.7)$ \\
\hline Mean age & $26(7.9)$ \\
\hline \multicolumn{2}{|l|}{ Gender } \\
\hline Female & $15(57.7)$ \\
\hline Male & $11(42.3)$ \\
\hline \multicolumn{2}{|l|}{ Ethnicity } \\
\hline Brahmin & $4(15.4)$ \\
\hline Chhetri & $3(11.5)$ \\
\hline Janjati(indigenous) & $17(65.4)$ \\
\hline Madhesi & $1(3.8)$ \\
\hline Dalit & $1(3.8)$ \\
\hline \multicolumn{2}{|l|}{ Education } \\
\hline Less than class $10 /$ illiterate & $17(65.4)$ \\
\hline $10^{\text {th }}$ passed or more & $9(34.6)$ \\
\hline \multicolumn{2}{|l|}{ Marital Status } \\
\hline Married & $15(57.7)$ \\
\hline Unmarried & $11(42.3)$ \\
\hline \multicolumn{2}{|l|}{ Religion } \\
\hline Hindu & $22(84.6)$ \\
\hline Buddhist & $4(15.4)$ \\
\hline \multicolumn{2}{|l|}{ Residence } \\
\hline Bhaktapur & $19(73.1)$ \\
\hline Surrounding Districts & $7(26.9)$ \\
\hline \multicolumn{2}{|l|}{ Occupation } \\
\hline Employed & $12(46.2 \%)$ \\
\hline Housewife & $7(26.9 \%)$ \\
\hline Student & $12(46.2 \%)$ \\
\hline
\end{tabular}

Table 1: Socio-demographic characteristics of the patients.

Details of suicide attempt

As shown in table 2, the most common method of suicide attempt was poisoning (65.4\%). One third of the patients had taken medications overdose and only one patient presented with hanging. Out of the poisoning cases, majority used organophosphorus 
Profile and Pattern of Suicide Attempts Among Admitted Patients in A Teaching Hospital: A Retrospective Study from Nepal

(82.3\%), followed by zinc phosphide (11.7\%) and Dettol (5.9\%). Out of those who presented with medication overdose, two third presented with NSAID overdose (Paracetamol, Brufen, Flexion) and one third presented with multiple drug overdose which included benzodiazepine and antidepressants (Mirtazapine, Escitalopram). $80 \%$ of patients reported that the poison and medications were available at their home and workplace and were in use for other purposes. Whereas one-fifth reported that they bought freely from shops for committing suicide. Similarly, $78.6 \%$ of those who consumed organophosphorus poison, had it available at home for pesticide control and $21.4 \%$ bought it from shops to commit suicide. Only few made attempts (15.4\%) when they were intoxicated with alcohol. Only one patient had past history of suicide and two had family history of suicide. Most of the attempts (73.1\%) were impulsive in nature i. e who were unplanned.

\begin{tabular}{|c|c|}
\hline Variables & Frequency (\%)/ Mean (S.D.) \\
\hline \multicolumn{2}{|l|}{ Method of suicide } \\
\hline Poisoning & $17(65.4)$ \\
\hline Medication overdose & $8(30.4)$ \\
\hline Hanging & $1(3.8)$ \\
\hline \multicolumn{2}{|c|}{ Sources of poison/medication $(n=25)$} \\
\hline Home/workplace & $20(80)$ \\
\hline Bought freely from shop & $5(20)$ \\
\hline \multicolumn{2}{|l|}{ Impulsive attempt } \\
\hline Yes & $19(73.1)$ \\
\hline No & $7(26.9)$ \\
\hline \multicolumn{2}{|c|}{ Attempt during Intoxication of alcohol } \\
\hline Yes & $4(15.4)$ \\
\hline No & $22(84.6)$ \\
\hline \multicolumn{2}{|c|}{ Past history of suicide attempt } \\
\hline Yes & $1(3.8)$ \\
\hline No & $25(96.2)$ \\
\hline \multicolumn{2}{|c|}{ Family history of suicide attempt } \\
\hline Yes & $2(7.6)$ \\
\hline No & $24(92.3)$ \\
\hline
\end{tabular}

Table2: Details of suicide attempt.

Clinical profile of the patients

The data (Table 3) shows that majority of patients (84.6\%) reported to have presence of stressor. Out of these, most of them had interpersonal conflicts (spouse, other family members, romantic relationship, workplace) (63.6\%), followed by financial problems (13.6\%), physical health issues (9.1\%), both health issues and interpersonal conflict (9.1\%) and academic problems (4.5\%) in descending order. About one-fourth had personality traits, out of which three-fourth had emotionally unstable personality traits and one had anxious(avoidant)personality traits. Diagnosis was made according to ICD-10. Most of the patients were diagnosed with depressive episode (38.5\%), out of which five patients had moderate depressive episode and two had severe depression without psychosis. Second most common diagnosis was adjustment disorder (19.2\%). Few patients were diagnosed with harmful use or dependence (alcohol harmful use, ADS, NDS) (7.7\%), anxiety NOS $(7.7 \%)$ and dual diagnosis (adjustment disorder and anxiety NOS with substance use comorbidity) (7.7\%). Six patients couldn't be diagnosed according to ICD -10. Less than one-third of the patients had history of substance use (alcohol, tobacco). Majority didn't have past (92.3\%) nor family history of psychiatric illness (88.5\%). Few had medical comorbidity $(n=2)$. Three-fourth of the patients received both pharmacological (antidepressant, benzodiazepine, thiamine and multivitamin supplements for alcohol dependence or harmful use) and non-pharmacological treatment (psychoeducation, few sessions of motivational enhancement therapy). Less than one-fifth received only non-pharmacological treatment. Majority of the patient didn't follow-up even once.

\begin{tabular}{|l|c|}
\hline Variables & $\begin{array}{c}\text { Frequency(\%)/ } \\
\text { Mean(S.D.) }\end{array}$ \\
\hline Stressor & $22(84.6)$ \\
\hline Present & $4(15.4)$ \\
\hline Absent & $14(63.6)$ \\
\hline Types of stressor (n=22) & $1(4.5)$ \\
\hline Interpersonal conflict & $3(13.6)$ \\
\hline Academic & $2(9.1)$ \\
\hline Financial & $2(9.1)$ \\
\hline Physical Health & \\
\hline $\begin{array}{l}\text { Both interpersonal conflict and physical } \\
\text { health }\end{array}$ & \\
\hline Presence of personality traits & $20(76.9)$ \\
\hline Yes & \\
\hline No & $5(19.2)$ \\
\hline ICD-10 Diagnosis & \\
\hline Adjustment disorder &
\end{tabular}




\begin{tabular}{|l|c|}
\hline $\begin{array}{l}\text { Depressive Disorder(Moderate depres- } \\
\text { sive episode \& Severe depression without } \\
\text { psychosis) }\end{array}$ & $10(38.5)$ \\
\hline Dual Diagnosis & $2(7.7)$ \\
\hline Harmful use or dependence & $2(7.7)$ \\
\hline Anxiety NOS & $1(3.8)$ \\
\hline No diagnosis & $6(23.1)$ \\
\hline Substance use history & $8(30.8)$ \\
\hline Yes & $18(69.2)$ \\
\hline No & $2(7.7)$ \\
\hline Past history of Psychiatric illness & $24(92.3)$ \\
\hline Yes & $21(80.8)$ \\
\hline No & $2(7.7)$ \\
\hline Medical comorbidity & $24(92.3)$ \\
\hline Yes & $2(19.2)$ \\
\hline No & $2(11.5)$ \\
\hline Family History of psychiatric illness & $2(88.5)$ \\
\hline Yes & \\
\hline No & \\
\hline Treatment received & \\
\hline Both pharmacological and non-pharma- \\
cological
\end{tabular}

Table 3: Clinical profile of the patients.

Special group

Impulsive attempters

Out of the attempters who were impulsive in nature $(n=19)$, majority belonged to young adulthood (63.2\%), females (52.6\%) and few had past history of psychiatric illness $(n=2$; adjustment disorder, suicidal attempt) and family history of psychiatric illness(n $=2$; ADS, suicidal attempt). One-fifth of them had a history of substance use. Most of them didn't have diagnosis according to ICD-10 (31.6\%) and adjustment disorder was the most common diagnosis $(26.3 \%)$. Poisoning was the most used method by majority of them. About $90 \%$ had stressor out of which interpersonal conflict was the predominant reason. All those with personality traits (n = 6; Emotionally unstable personality $=5$, anxious(avoidant) personality traits) and those who were intoxicated $(n=4)$ during the suicidal attempt made impulsive attempt.
Gender

There was no significant difference found between males and females in socio-demographic and clinical characteristics including details of suicide attempt except that female attempters were found to prefer medication overdose and male attempters were found to prefer poisoning methods. Similarly males attempted suicide while they were intoxicated with alcohol more than female. There was significant difference in their method of choices and attempts during intoxication (Table 4).

\begin{tabular}{|l|c|c|c|}
\hline Variables & $\begin{array}{c}\text { Female } \\
(\mathbf{N}=15)\end{array}$ & $\begin{array}{c}\text { Male } \\
(\mathbf{N}=11)\end{array}$ & $\begin{array}{c}\text { 2/Fisher's(df); } \\
\text { p-value }\end{array}$ \\
\hline Methods of suicide \\
\hline Hanging & 0 & 1 & $0.01^{* a}$ \\
Overdose & 8 & 0 & \\
Poisoning & 7 & 10 & \\
\hline Attempt during intoxication of alcohol \\
\hline No & 15 & 7 & $0.02^{* a}$ \\
Yes & 0 & 4 & \\
\hline
\end{tabular}

Table4: Group comparison on details of suicide attempt

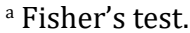

\section{Discussion}

The chief finding of our study was that the typical profile of suicide attempters was that of females belonging to the age group of young adults and majority of the attempts were found to be impulsive in nature with the most common method being poisoning.

Nepal has one of the highest rates of suicide in the world. However, few research have taken place addressing geographic and socio-cultural variation and comparing patterns of suicide attempt between males and females. Attempted suicides are 10 - 20 times more frequent than fatal suicides [9]. Hence it is imperative to study about suicide attempt so that appropriate suicide prevention strategies can be made.

This is the first teaching hospital based study carried out in Bhaktapur, the smallest district of Nepal. Previous studies have found out that suicide is more prevalent in younger age group, females and among homemakers and students [7,10-15]. Women during reproductive age group have been found vulnerable to mental health issues including suicide $[14,15]$. In a government survey carried out in eight districts between 2008 - 2009, suicide (16\%) 
was leading cause of death than maternal related issues $(12 \%)$ in 86,000 women of reproductive age group. This in line with our study. Women have various challenges in Nepalese society such as poor empowerment, lack of opportunities in education, job, early marriages [16]. These make them a vulnerable group in the society. However, a study which conducted psychological autopsy of random police cases between 2013 - 2015 found more males than females [17]. Studies have shown women frequently attempt suicide and males complete suicide more $[18,19]$. That may be the reason why females attempters are more in hospital based studies like ours for treatment purpose. Males use hanging method more commonly and therefore have higher risk of death and may reach to police than to hospitals.

Majority of the patients belonged to indigenous group and did not enter high school. This was similar to previous studies. [10-12] Indigenous group of people are at disadvantage in the community since they face various social hardships such as lower socioeconomic status, poor education less access to social services and other economic opportunities [6]. Moreover, Bhaktapur has higher proportion of indigenous people and this could have probably led to our results. The predominant subjects were Hindu, married. This can be explained with the fact that majority of population is Hindu in Nepal. [6] Since majority were young adults, hence our subjects were mostly married.

The study showed self-poisoning with pesticides, especially organophosphorus as the most common method of suicidal attempt similar in findings with other studies hospital based [13]. This is unlike the study carried out in 2003 in Bhaktapur district hospital where zinc phosphide was the most common poison found [20]. The difference in the reports over 16 years may be because of the increase in need of pesticides for farming and thereby increased availability of organophosphorus in community. Bhaktapur district is considered a suitable area for vegetable farming and is a major area for production of commercial vegetables. [21] Pesticide use has led to increased productivity but at the same time led to its rampant use [22]. Even though few were farmers, majority subjects had organophosphorus at home and about one-fifths bought it freely from shop for suicidal attempt. This highlights mishandling of pesticides, its indiscrete use even for non-commercial purpose and lack of strong enforcement of regulations and laws on pesticides application and sale. Second most common method was the medication overdose. In our study, majority reported availability of poison and medications at home. Therefore, it is important to keep away such items away from those vulnerable and to educate patients who need medications such as benzodiazepine, psychotropics, NSAID about its safe storage. Contrary to our findings, hanging has been found to be the most common method of suicide in post-mortem studies [17,23]. The difference may have occurred as hanging could have more fatality and therefore may reach to police than poisoning cases who are taken to hospitals for treatment. To understand the most common method in the community, it is essential to conduct community based studies.

Very few had emotionally unstable traits like previous study $[13,20]$ Our study showed that there was no follow-ups. Hence, less interaction with patient and family members could have led to difficulty to evaluate premorbid personality of the patients. Most common diagnosis of the suicide attempters was depressive episode. About two-fifths of the suicide attempters were diagnosed with depressive episode. This finding is consistent with previous studies $[10,13,17,24-26]$. Less than one-third had history of substance use, therefore very few had attempts while intoxicated with alcohol. No cases of psychosis were noted unlike [13] Small sample size and accessibility to hospitals in nearby bigger cities of Kathmandu and Lalitpur might have influenced the result. About one-fourth of the patients couldn't be diagnosed for their condition according to ICD - 10. It is the limitation of ICD - 10 that impulsive attempts doesn't find a place in the diagnosis. Therefore can get missed. Therefore, psychiatric evaluations should not just be focussed on diagnosing patients with psychiatric disorder. Those with risk factors should be identified and managed accordingly. Research has shown considerable number of suicidal attempts are impulsive in nature $[13,27,28]$. Impulsive suicidal attempts were associated with alcohol use [29], younger age group [30], more previous suicidal attempt [30], less fatal methods [30] and interpersonal conflicts [32]. Impulsivity is found in patients with personality disorder, substance use disorder [33]. Our study had similar findings. However, our sample showed suicidal attempts with impulsivity taking lethal method such as self-poisoning for suicide. This may be because pesticides, rodenticides were available at home. This emphasizes need to understand relationship between impulsive suicidal attempt and other variables so that risk factors can be identified and intervened. It will be important to explore vulnerability of these specific groups and their risk of suicide in future studies. 
Several studies carried out earlier in Nepal has described psychosocial factors like interpersonal conflicts with husbands and unhappy marriages $[5,7,24]$ domestic violence, academic failure, break up with romantic partner, health issues [24,26,34] largely contributing to suicides. Our study also imparts similar information. It is necessary that any patient with ongoing psychosocial stressor has to be evaluated for suicide risk, ptychodontid and provided primary or secondary prevention.

Globally, men have been found to commit suicide by hanging, firearms and females would mostly resort to psychoactive substances and poisoning [35]. Firearms isn't common in Nepal and this being hospital based study, hanging cases possible reach to police due to its high lethality. Therefore only one case of suicidal attempt by a male patient was seen. Females preferred medications overdose than males and males opted for self poisoning more. Such gender differences hasn't been studied in Nepal. A possible explanation to our result is women intentionally use less lethal suicide method to draw attention to their situation and don't intend to die. Males are more likely to use impulsive, lethal attempts as they are prone to aggressive and externalizing behaviours and nonfatal suicidal behaviour is associated with felinity. [9] Self-poisoning could be considered more lethal suicide method due to increased media reporting and awareness in societies about its increased use as a suicidal method. Hence was preferred by males.

Alcohol is common in households of Bhaktapur as it is offered to god, used in festivals and is also prepared at home. Study done in Bhaktapur among youths found that 565 youths reported current drinking where males (37.6\%) outnumbered females (18.4\%). [36] Alcohol has been identified as a risk factor for suicide attempts among those with and without alcohol use disorder $[37,38]$. Moreover, being intoxicated with alcohol may increase the risk of individual for suicidal thought and attempts [38]. Furthermore, males are associated with high risk of suicidal attempt under the influence of alcohol [40,41-46]. Our study has similar findings of males attempting more suicidal attempt during intoxication than females. Therefore, it is important to examine risk of suicide and prevent suicidal behaviours among those who consume alcohol even when they don't report suicidal thoughts.

The strengths of the study are the study site Bhaktapur, though a vulnerable place yet unexplored on suicide, inclusion of the clinical evaluations by an expert, gender comparison of profile and pattern of suicide attempt. However, there are several limitations of the study. It is a hospital based study with retrospective study design of one year duration with small sample size. Hence the results can't be generalized. Impulsivity was noted on basis of clinical interview by psychiatrist There was no scale to measure impulsivity objectively. History of substance use was based on only using self-report without relying on structured instruments or urine for drug screen. Future studies with robust methodology are needed to know common methods used in the community. National surveys, longitudinal and qualitative studies are needed to know protective and aggravating factors, influence of sociocultural and geographical variation, gender differences, various age-groups, roles of impulse, substance use and personality factors and efficacies of prevention strategies and intervention adaptive to the needs of the community.

\section{Conclusion}

Suicide in Nepal is a common and serious problem requiring immediate attention and systematic efforts. Suicide attempts were common in young females belonging to indigenous community. Attempts were predominantly impulsive in nature triggered by mostly psychosocial stressors in subjects with underlying psychiatric comorbidities and easy availability of means of suicide such as poisons and medication overdose. Gender difference was present in methods of suicide attempt and attempts made during alcohol intoxication. Prevention strategies should be tailored to address gender differences, different age-groups, socio-cultural-economic background and psychiatric comorbidities of the population and geographic variations of the community.

\section{Conflict of Interest}

None.

\section{Bibliography}

1. World Health Organization. Preventing Suicide: A Global Imperative. World Health (2014).

2. World Health Organization (2019).

3. Jha AK., et al. "Prevalence of mental disorders in Nepal: findings from the pilot study". Journal of Nepal Health Research Council 17.2 (2019): 141-147.

4. Cousins S. "Nepal's silent epidemic of suicide". Lancet 387.10013 (2016): 16-17.

5. Suvedi B., et al. "Maternal Mortality and Morbidity Study 2008/2009: Summary of Preliminary Findings” (2009). 
6. Central Bureau of Statistics, Government of Nepal. "National Population and Housing Consensus 2011(volume01, NPHC11) Kathmandu, Nepal: National Planning Comission" (2012).

7. Ghimire S., et al. "Psychiatric Comorbidities in Patients with Deliberate Self-Harm in a Tertiary Care Center". Journal of the Nepal Medical Association 52.193 (2014).

8. Verhaeghe M., et al. "Stigmatization in different mental health services: a comparison of psychiatric and general hospitals". The Journal of Behavioral Health Services and Research 34.2 (2007): 186-197.

9. Beautrais AL. Suicide in Asia (2006).

10. Chakrabarti K and Devkota KC. "Retrospective study of suicide cases admitted in Nepal Medical College Teaching Hospital”. Nepal Medical College Journal 6.2 (2004): 116-118.

11. Kafle B., et al. "Sociodemographic profile and Psychiatric diagnosis in attempted suicide". Journal of Psychiatrists' Association of Nepal 5.1 (2016): 22-25.

12. Shakya DR. "Common stressors among suicide attempters as revealed in a psychiatric service of Eastern Nepal”. Journal of Traumatic Stress Disorders \& Treatment. 3 (2014): 2.

13. Thapaliya S., et al. "Pattern of suicide Attempts in southern nepal: A Multi-centered retrospective study". Med Phoenix 3.1 (2018): 41-47.

14. Patel V., et al. "Suicide mortality in India: a nationally representative survey". The Lancet 379.9834 (2012): 2343-2351.

15. Sharma GK. "Leading causes of mortality from diseases and injury in Nepal: a report from national census sample survey". Journal of Institute of Medicine 28.1 (2007).

16. Perczynska A and Coyle D. Child marriage as a health issueNepal case study. New York: United Nations Human Right Office of the High Commissioner (2013).

17. Hagaman A. K., et al. "Suicide in Nepal: a modified psychological autopsy investigation from randomly selected police cases between 2013 and 2015". Social Psychiatry and Psychiatric Epidemiology 52.12 (2017): 1483-1494.

18. Tsirigotis K., et al. "Gender differentiation in methods of suicide attempts". Medical Science Monitor: International Medical Journal of Experimental and Clinical Research 17.8 (2011): PH65.
19. Runeson B., et al. "Method of attempted suicide as predictor of subsequent successful suicide: national long term cohort study". BMJ 341 (2010): 3222.

20. Ghimire S., et al. "Psychiatric Comorbidities in Patients with Deliberate Self-Harm in a Tertiary Care Center". Journal of the Nepal Medical Association 52.193 (2014).

21. Budhathoki., et al. "Handling Pattern of Pesticides in Vegetables: A Case Study of Bhaktapur". Journal of Science and Engineering 6 (2019): 29-39.

22. Pimentel D., et al. "Environmental and economic effects of reducing pesticide use in agriculture". Agriculture, Ecosystems and Environment 46.1-4 (1993): 273-288.

23. Upadhyaya KD and Pol K. "Suicide in Kaski district". Journal of Institute of Medicine 20.3 (2007).

24. Pradhan A., et al. "A Review of the Evidence: Suicide Among Women in Nepal. National Health Sector Support Program". Ministry of Health and Population, Kathmandu (2011): 117.

25. Sapkota N., et al. "Hundred psychiatric outpatients presented with attempted suicide". Health Renaissance 9.3 (2011): 162167.

26. Benson J and Shakya R. "Suicide prevention in Nepal: a comparison to Australia-a personal view". Mental Health in Family Medicine 5.3 (2008): 177.

27. Perez VW. "The relationship between seriously considering, planning, and attempting suicide in the youth risk behavior survey". Suicide and Life-Threatening Behavior 35.1 (2005): $35-49$.

28. Baca-Garcia E., et al. "Suicide attempts and impulsivity". European Archives of Psychiatry and Clinical Neuroscience 255.2 (2005): 152-156.

29. Koller G., et al. "Impulsivity and aggression as predictors of suicide attempts in alcoholics". European Archives of Psychiatry and Clinical Neuroscience 252.4 (2002): 155-160.

30. Lim M., et al. "Differences between impulsive and non-impulsive suicide attempts among individuals treated in emergency rooms of South Korea". Psychiatry Investigation 13.4 (2016): 389.

31. Dougherty DM., et al. "Suicidal behaviors and drug abuse: impulsivity and its assessment". Drug and Alcohol Dependence 76 (2004): S93-S105. 
32. Bi B., et al. "Personality traits and suicide attempts with and without psychiatric disorders: analysis of impulsivity and neuroticism". Bmc Psychiatry 17.1 (2017): 294.

33. Moeller FG., et al. "Psychiatric aspects of impulsivity". American Journal of Psychiatry 158.11 (2001): 1783-1793.

34. Mishra N., et al. "Retrospective study of suicide among children and young adults". Journal of Nepal Paediatric Society 33.2 (2013): 110-116.

35. Sadock BJ., et al. Kaplan and Sadock's Comprehensive Textbook of Psychiatry (10th edition). China: Wolters Kluver (2017).

36. Maharjan PL and Magar K. Patterns of Alcohol consumption among the youths of Bhaktapur, Nepal. Latvia, European Union: Lap LAMBERT Academic Publishing (2017).

37. Hufford MR. "Alcohol and suicidal behaviour". Clinical Psychology Review 21.5 (2001): 797-811.

38. Giancola PR. "Irritability, acute alcohol consumption and aggressive behavior in men and women". Drug and Alcohol Dependence 68.3 (2002): 263-274.

39. Mościcki EK. "Identification of suicide risk factors using epidemiologic studies". Psychiatric Clinics of North America 20.3 (1997): 499-517.

40. Hayward L., et al. Blood alcohol levels in suicide cases. Journal of Epide World Health Organization, 2014. Preventing Suicide: A Global Imperative. World Health (1992).

41. Organization, Geneva Retrieved (2017).

42. Mental_health/suicide-prevention/world_report_2014/en/.

43. Nepal police suicide data (2016).

44. Pradhan A., et al. "Suicide: attempts methods and causes in cases brought for autopsy in Bpkihs, Dharan". Journal of Forensic Research 3.166 (2012): 2.

Volume 3 Issue 12 December 2019

(C) All rights are reserved by Bigya Shah., et al. 